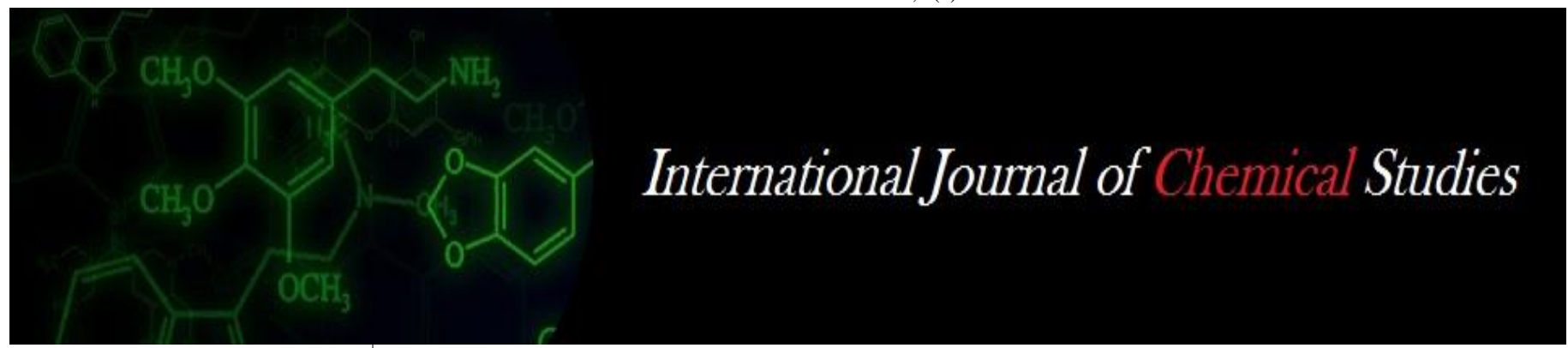

P-ISSN: 2349-8528

E-ISSN: 2321-4902

www.chemijournal.com

IJCS 2021; 9(1): 2492-2495

(C) 2021 IJCS

Received: 19-10-2020

Accepted: 24-11-2020

Garima Bartariya

Department of Life Sciences,

ITM University, Gwalior,

Madhya Pradesh, India

\section{Neha Chauhan}

Department of Life Sciences, ITM University, Gwalior,

Madhya Pradesh, India

Varsha Chauhan

Department of Life Sciences, ITM University, Gwalior, Madhya Pradesh, India
Corresponding Author:

Neha Chauhan

Department of Life Sciences,

ITM University, Gwalior,

Madhya Pradesh, India

\section{Secondary metabolites assessment: In vitro Antiarthritic and antihemolytic potential of various extracts of ginger}

\author{
Garima Bartariya, Neha Chauhan and Varsha Chauhan
}

DOI: https://doi.org/10.22271/chemi.2021.v9.i1ai.11602

\begin{abstract}
Herbal medicines are are one of the dietary supplements to maintain or improve health. They are used as prophylactic and therapeutic agents. Zingiber offecinale is widely used around the world in food as the spice. The primary pungent agents (phenylalkylketones or vanilyl ketones) of ginger are gingerol with other general analogues such as the shogoals, paradole and zinger one. Present study is of primary and secondary metabolite assessment based in which main focus is on anti-arthritic and antihemolytic activity of ginger extracts. Preliminary screening shows the presence of carbohydrate and protein, alkaloids saponins, steroids and tannins. In vitro anti-arthritic study showed the inhibition of protein denaturation which indicated that the ginger extracts are capable of controlling the production of auto antigens. Another study of antihemolytic activity indicate the capacity of Ginger extract to reduce hemolysis of RBC. Further the FTIR- spectra of Zingiber has also been performed for rapid determination and identification of various functional groups responsible for the medicinal properties such as phenolics, ether, aromatics, carboxylic acid and alcohol.
\end{abstract}

Keywords: Herbal drugs, secondary metabolites, zingiber officinales, antiarthritis, antihaemolytic

\section{Introduction}

Herbal medicines are one of dietry suppliments to maintain or improve health. They are used as prophylactic and therapeutic agents against hepatic, renal, cardiovascular as well as inflammatory diseases, by modulating risk factors such as hypertension, high blood cholesterol, thrombosis, and preventing other chronic diseases associated with ageing (Rahman 2001, Tanaka et al., 2006, Rahman, 2003, Neil et al., 1994) ${ }^{[16,17] .}$

World Health Organisation (WHO) reported that about $80 \%$ of the world's population depend mainly on traditional medicine and the traditional treatment involve mainly the use of plant extracts. Secondary plant metabolites play a very important role and have bio applications. Natural antioxidants are the secondary metabolites of the plant and do not have side effects when taken in vivo (Chen et al., 1992; Walton and Brown, 1999) ${ }^{[4]}$. Many plants contain wide variety of free radicals scavenging molecule such as phenolic compounds, nitrogen compounds, vitamins and terpenoids. Some other endogenous metabolites phenolic compounds are also present which are important secondary metabolites and having redox properties which neutralizes the free radicals there by quenching singlet and triplet oxygen decomposing peroxides as an important antioxidant (Osawa, 1994) ${ }^{[12]}$. Tannins also found to be as a potential agent in variety of disease states (Packer et al., 1999) ${ }^{[14]}$.

Ginger (Zingiber officinale, Zingiberaceae) is widely used around the world in foods as a spice. Ginger is a perennial rhizome and cultivated in the tropical climates of Australia, Brazil, China, India, Jamaica, West Africa, and parts of the United States (Langner et al., 1998) ${ }^{[20]}$. Ginger rhizome was traditionally used in Chinese and Ayurvedic medicine as an antiemetic, antipyretic, and anti-inflammatory agent (Leung AY. Chinese Herbal Remedies, Universe Books, New York, 124). The constituents of ginger are numerous and vary depending on the place of origin and whether the rhizomes are fresh or dry. The primary pungent agents (phenylalkylketones or vanillyl ketones) of ginger are gingerol, with other gingerol analogues such as the shogoals, paradol and zingerone also found in high levels in rhizome extracts. The major pharmacological activity of ginger appears to be due to gingerol and shogaol (Duke and Beckstrom 1999). Phenylalkyl ketones or vanillyl ketones of ginger 
include 6-gingerol 8-gingerol and 10-gingerol, 6-shogaol, 8shogaol, 10-shogaol and zingerone. 6-paradol, 6- and 10dehydrogingerdione and 6- and 10-gingerdione have also been identified. (Chrubasik et al., 2007) ${ }^{[5]}$.

\section{Materials and Methods}

\subsection{Collection of Material}

For the present study, fresh ginger rhizome were collected from nearby crop field of ITM University campus. Collected ginger rhizome was weighed to $1000 \mathrm{gm}$ and cleaned properly.

\subsection{Preparation of Methanolic Extract}

Cleaned ginger was peeled and cut in to small pieces and shade dried. Dried rhizomes were powdered using mixergrinder and subjected to Soxhlet extraction,. Fifty grams of powder has been sequentially extracted with methanol and water respectively in soxhelet apparatus for $72 \mathrm{~h}$. The obtained crude extract was dried in rotatory evaporator and stored in air tight container in refrigerator. These condensed extracts were used for the presence of various bioactive compounds by following standard methods. (Kumar et al., 2012 ${ }^{[8]}$.

\subsection{Preparation of aqueous extract}

Fifty grams of powder has been extracted with water in soxhelet apparatus for $72 \mathrm{hrs}$. The obtained crude extract was air dried in Rotatory evaporator. After evaporation the obtained powdered extract was used for various biochemical analysis (Kumar et al., 2012) ${ }^{[8]}$.

\subsection{Phytochemical analysis of primary metabolites}

The prepared extracts were used for Preliminary phytochemical screening for the presence of basic primary metabolites like carbohydrates, proteins and lipids (Plummer, 1987) ${ }^{[15]}$

\subsubsection{Carbohydrates}

For carbohydrate screening, dried extracts were dissolved individually in $5 \mathrm{ml}$ distilled water and filtered through whattman filter paper 1. Molisch's test and Fehling's test was performed by using this filterate for the presence of carbohydrates and reducing sugars respectively.

\subsubsection{Proteins}

Presence of protein in the sample was tested by performing most suitable and appropriate test i.e. Biuret and Ninhydrin. Protocol of these tests are as follows:

2.4.3. Biuret's test: For this screening $1 \mathrm{ml}$ of test extract, was added with $4 \%$ of sodium hydroxide solution and few drops of $1 \%$ copper sulphate solution. After few minutes, mixture becomes of violet and red colour which indicated the presence of peptide bond.

2.4.4. Ninhydrin test: For this laboratory assay a few drops of $0.25 \%$ of ninhydrin in acetone was added in $2 \mathrm{ml}$ of test extract. Then the mixture has been heated in boiling water bath for $10 \mathrm{~min}$. The formation of bluish purple colour in the tube indicated the presence of amino acid. (Kumar et al., 2012 ${ }^{[8]}$

\subsection{Phytochemical analysis of secondary metabolites}

Secondary metabolites were screened in the prepared test extract for the presence of alkaloids, reducing sugars, proteins, flavonoids, tannins, phenols, phytosterol and saponins by using the standard procedures. (Kumar et al., 2012 ${ }^{[8]}$.

\subsubsection{Alkaloids}

Alkaloids were detected by using Wagner's test. For this $2 \mathrm{ml}$ of extracts was mixed with $2 \mathrm{ml}$ of Wagner's reagent $(1.27 \mathrm{gm}$ of Iodine and $2 \mathrm{gm}$ of $\mathrm{KCl}$ in $100 \mathrm{ml}$ distilled water). Formation of brownish- red precipitate indicates the presence of alkaloids.

\subsubsection{Saponins by Froth test}

Saponins was tested by Forth formation test. For this $2 \mathrm{ml}$ extract was diluted with distilled water to $20 \mathrm{ml}$ and shaken vigorously in a graduated cylinder for 15 seconds. Formation of persistent foam layer of approximately $1 \mathrm{~cm}$ at the surface indicate the presence of saponins in the extract. This froth become stable for 1 minute.

\subsubsection{Steroids by Salkowski test}

Five milligram of extract was added with $2 \mathrm{ml}$ of chloroform and $2 \mathrm{ml}$ of conc. Sulphuric acid. Tubes were shaken and vigourously and allowed to kept at normal temperature for selling down. A golden yellow red colour indicated the presence of phytosterols.

\subsubsection{Tannins (ferric chloride test)}

For tannins ferric chloride test was conducted by using solvent extract. Crude extract $(1 \mathrm{ml})$ was taken in a test tube and added with 500microlitre of $\mathrm{FeCl} 3$ solution (2\%); an intense green, purple, blue or black colour developed was taken as an evidence for the presence of tannins in foliar extract.

\subsection{In-vitro anti-arthritic activity by inhibition of protein denaturation method}

- The test experimental $(0.5 \mathrm{ml})$ consist of $0.45 \mathrm{ml}$ of Bovine serum albumin (5\%w/v aqueous solution) and $0.05 \mathrm{ml}$ of test solution $(250 \mu \mathrm{g} / \mathrm{ml})$.

- Test control solution $(0.5 \mathrm{ml})$ consist of $0.45 \mathrm{ml}$ of bovine serum albumin $(5 \% \mathrm{w} / \mathrm{v}$ aqueous solution) and $0.05 \mathrm{ml}$ of distilled water.

- Product control $(0.5 \mathrm{ml})$ consists of $0.45 \mathrm{ml}$ of distilled water and $0.05 \mathrm{ml}$ of test solution $(250 \mu \mathrm{g} / \mathrm{ml})$.

- Standard solution $(0.5 \mathrm{ml})$ consists of $0.45 \mathrm{ml}$ of Bovine serum albumin $(5 \% \mathrm{w} / \mathrm{v}$ aqueous solution) and $0.05 \mathrm{ml}$ of diclofenac sodium $(250 \mu \mathrm{g} / \mathrm{ml})$.

All the above solutions were adjusted to $\mathrm{pH} 6.3$ using $\mathrm{HCl}$ $(1 \mathrm{~N})$. The samples were incubated at $37^{\circ} \mathrm{C}$ for 20 minutes and the temperature was increased to keep the samples at $57^{\circ} \mathrm{C}$ for 3 minutes. After cooling, $2.5 \mathrm{ml}$ of phosphate buffer was added to the above solutions. The absorbance was measured using UV- Visible spectrophotometer at $416 \mathrm{~nm}$ (Venkataraman et al., 2013) ${ }^{[19]}$. The percentage inhibition of protein denaturation can be calculated as:

Percentage Inhibition $=[100-($ optical density of test solution optical density of product control) / (optical density of test control)] $\times 100$.

The control represents $100 \%$ protein denaturation. The results were compared with standard diclofenac sodium. The percentage inhibition of protein denaturation of different concentration was tabulated. 


\subsection{Heat induced haemolysis}

Reaction mixture $(2 \mathrm{ml})$ consisted of $1 \mathrm{ml}$ test solution and 1 $\mathrm{ml}$. of $10 \% \mathrm{RBC}$ suspension. Saline was replaced with drug in test solution. Aspirin was taken as a standard drug. The tubes were incubated in a water bath at $560 \mathrm{C}$ for $30 \mathrm{~min}$. At the end of the incubation, the tubes were cooled under running tap water. Reaction was centrifuged at $2500 \mathrm{rpm}$ for 5 minutes and OD of supernatant taken at $560 \mathrm{~nm}$ with UVvisible spectrophotometer (Okoli et al., 2008) ${ }^{[13]}$.

\subsection{FTIR Spectroscopy}

The FTIR from 4000 to $400 \mathrm{~cm}^{-1}$ was recorded on a PerkinElmer (spectrum 2) spectrometer. FTIR is used as a tool for the characterization and identification of compounds or functional groups (chemical bonds) present in an unknown mixture of plants extract (Eberhardt et al., 2007; Hazra et al., 2007) ${ }^{[6]}$.

\section{Results and Discussion}

Phytochemicals, also known as secondary metabolites, are biologically active, which have many health benefits. Results of the phytochemical screening of the extracts showed the presence of flavonoids, steroids, tannins and reducing sugars in both the aqueous and ethanolic extracts. Aalkaloids and saponins can be traced only in the ethanolic and aqueous extracts respectively (Table 1). Flavanoids have strong history in ayurvedic medicine and also have various uses in skin protection, normal brain function, maintaining blood sugar level and blood pressure regulation. Flavonoid is one of the main group of phenolic compound and widely distributed flavonoid, flavones and flavonols. Flavonoids and phenolics are the effective scavengers of the free radicals and chain breaking agents due to presence of hydroxyl group. Their presence indicates high analgesic and anti-inflammatory effects as a result of their membrane stabilizing ability against free radicals produced as a result of lipid peroxides and superoxides which causes cell membrane destabilization. It also possess anticancer, anti- diabetic, anti-aging properties and prevention of cardiovascular diseases. Tannins possess antiviral, antibacterial and antiparasitic effects and have the potential to fight against cancer.

In the present study the antioxidant activity of the sample remain very high which is possibly due to its high phenolic and flavonoid content. Polyphenolic and flavanoid compounds contain conjugate ring structures and hydroxyl groups; which aids in providing an antioxidant status in cell free systems by scavenging singlet oxygen, superoxide anion, lipid peroxy radicals, hydroxyl ions, nitric oxide ions, and stabilizing free radicals involved in oxidative processes (Aliyu, B.S. 2006) ${ }^{[1]}$

Table 1: Phytochemical Characteristics of Aqueous and Ethanolic Extracts of Z. Officinale

\begin{tabular}{|c|c|c|c|c|c|c|}
\hline Extract & Alkaloids & Saponins & Flavonoids & Steroids & Tannins & Reducing sugar \\
\hline Ethanolic & + & - & + & + & + & + \\
\hline Aqueous & - & + & + & + & + & + \\
\hline
\end{tabular}

KEY: $+=$ present

$-=$ absent

Table 2 depicts the in-vitro antiarthritic activity by inhibition of protein denaturation. The inhibition of protein denaturation was observed in the methanolic extract of ginger significantly at $800 \mu \mathrm{g} / \mathrm{ml}(65 \%)$ as compared to standard drug i.e. diclofenac sodium. The aqueous extract of ginger powder showed significant activity at $800 \mu \mathrm{g} / \mathrm{ml}(40 \%)$ by inhibition of protein denaturation as compared to the standard drug diclofenac sodium.

The production of auto antigen (like Rheumatoid Factor) in certain arthritic disease is because of protein denaturation. Hence we can conclude that the methanolic extract of ginger are capable of controlling the production of auto antigen or functional groups (chemical bonds) present in an unknown mixture of plant extracts. (Londhe et al., 2020) ${ }^{[11]}$.

Table 2: Effect of aqueous and methanolic extract of ginger on protein denaturation

\begin{tabular}{|c|c|c|}
\hline Treatment & Concentration $(\boldsymbol{\mu g} / \mathbf{m l})$ & Inhibition (\%) \\
\hline \multirow{2}{*}{ Diclofenac sodium } & 200 & 89.20 \\
\cline { 2 - 3 } & 300 & 92.46 \\
\hline & 500 & 92.50 \\
\hline \multirow{2}{*}{ Methanolic Extract } & 800 & 98.67 \\
\cline { 2 - 3 } & 200 & 36.00 \\
\hline & 300 & 44.00 \\
\hline & 500 & 52.00 \\
\hline \multirow{2}{*}{ Aqueous Extract } & 800 & 65.00 \\
\cline { 2 - 3 } & 200 & 17.00 \\
\hline & 300 & 20.00 \\
\hline
\end{tabular}

Table 3 explains the antihaemolytic activity of the extract in the presence of, where ascorbic acid was taken as a positive control. It was observed that when RBC cell were treated with $\mathrm{H}_{2} \mathrm{O}_{2}$ along with two different extract, there was a marked reduction in the haemolysis whereas the cells treated with the toxicant alone remain as such. When cells were treated with the extract alone, no haemolysis was resulted which explain the non-toxic behaviour of the extracts on human RBC. Out of all extract, methanolic extract was superior than others. Both methanolic and aqueous extracts demonstrated a significant inhibition of hemolysis in in vitro studies. The inhibition occur in crude extracts of ginger at comparatively lower concentrations $(37.5 \mu \mathrm{g} / \mathrm{ml})$ was comparable with that of standard anti-hemolysis compounds such as aspirin. This experimental evidence indicates that aqueous and methanolic extracts could have a potential therapeutic efficacy in disease processes causing destabilization of biological membrane. (Anwar et al. 2020) ${ }^{[2]}$

Tissue proteins are denatured causing production of auto antigens an arthritic disesases leading to inflammatory and arthritic diseases. Proteins denaturation sometimes causes alteration in electrostatic, hydrogen, hydrophobic and disulphide boding and observation of this study indicate such type of mechanism of action by ginger constituents. From the result of the present study it can be concluded that Zingiber officinaleis is capable of controlling the production of auto antigens due to in- vivo denaturation of proteins in rheumatic diseases. Protective effect on heat and hyotonic salineinduced erythrocyte lysis is known to be a very good index of anti- arthritic activity of any agent. Such type of results are 
also observed by Brown and Mackey, $1968^{[3]}$, since the membrane of RBC is structurally similar to the lysosomal membrane, the effect of any substance on stabilization of RBC membrane may be extrapolated to the stabilization of lysosomal membrane.

Table 3: Effect of ginger on heat induced hemolysis

\begin{tabular}{|c|c|c|}
\hline Treatment & Concentration $((\boldsymbol{\mu g} \mathbf{g} \mathbf{m l})$ & Inhibition (\%) \\
\hline \multirow{4}{*}{ Aspirin } & 200 & 89.20 \\
\cline { 2 - 3 } & 300 & 98.67 \\
\cline { 2 - 3 } & 500 & 92.46 \\
\cline { 2 - 3 } & 800 & 92.50 \\
\hline \multirow{4}{*}{ Methonolic Extract } & 200 & 51.00 \\
\cline { 2 - 3 } & 300 & 48.00 \\
\cline { 2 - 3 } & 500 & 42.00 \\
\hline \multirow{3}{*}{ Aqueous Extract } & 800 & 31.00 \\
\cline { 2 - 3 } & 200 & 44.00 \\
\cline { 2 - 3 } & 300 & 26.00 \\
\cline { 2 - 3 } & 500 & 21.00 \\
\cline { 2 - 3 } & 800 & 13.00 \\
\hline
\end{tabular}

Figure 1 Showing the FTIR spectra for the Zingiber officinale. The present study of FTIR spectroscopy was performed for easy and rapid determination and identification of various functional groups responsible for medicinal properties. IR spectroscopy is basically a vibrational spectrum. The results indicated the presence of several functional groups such as phenolic, ether, aromatic, carboxylic acid, and alcohols are responsible for various medicinal properties of ginger

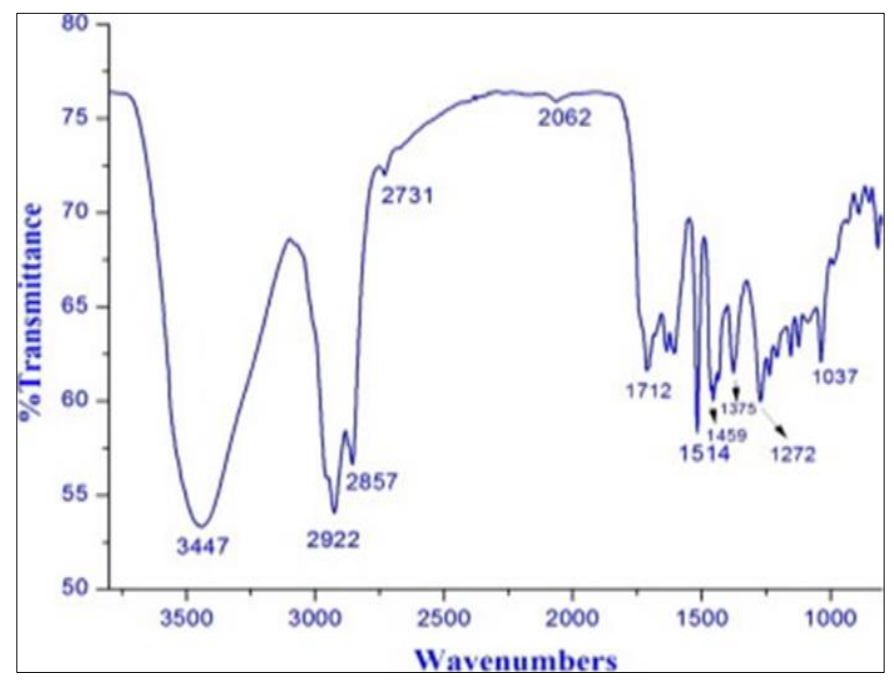

Fig 1: FTIR spectra for the Zingiber officinale extracts

\section{References}

1. Aliyu BS. Common ethno-medicinal plants of the semiarid regions of West Africa their descriptions and phytochemicals Triumph publishing company Limited, GidanSa'adu Zungur, Kano, Nigeria 2006.

2. Anwar S, Almatroudi A, Allemailem KS, Joseph RJ, Khan AA, Rahmani AH. Protective Effects of Ginger Extract against Glycation and Oxidative Stress-Induced Health Complications: An in vitro Study Processes 2020;8(4):468.

3. Brown JH, Mackey HK. Inhibition of heat induced denaturation of serum proteins by mixtures of nonsteroidal anti-inflammatory agents and amino acids. Proc. Soc. Exp. Biol. med 1968;128:225-28.
4. Chen C, Pearson AM, Gray IJ. Effects of synthetic antioxidants (BHA, BHT and PG) on the mutagenicity of IQ-like compounds. Food Chemistry 1992;43:177-183.

5. Chrubasik JE, Roufogalis BD, Chrubasik D. Evidence of effectiveness of herbal anti-inflammatory drugs in the treatment of painful osteoarthritis and chronic low back pain Phytother Res 2007;21:675-683.

6. Eberhardt TL, Li X, Shupe TF, Hse CY. Chinese Tallow ree (Sapium Sebiferum) utilization: Characterization of extractives and cell-wall chemistry. Wood Fiber Sci 2007;39:319-324.

7. Hwang IG, Woo KS, Kim DJ, Hong JT, Hwang BY, Lee YR et al. Isolated and identification of an antioxidant substance from heated garlic (Allium sativum L.). Food Sci Biotechnol 2007;16:963-966.

8. Kumar S, Sharma UK, Sharma AK, Pandey AK. Protective efficancy of Solanum xanthocarpum root extracts against free redical damage: Phytochemical analysis and antioxidant effect. Cell. Mol. Biol 2012;58(1):174-181.

9. Isaac John Umaru, Saad Ismail Shuaibu, Rufaidat Baba Adam, Bilyaminu Habibu, Kerenhappuch Isaac Umaru, David Ephraim Haruna. Bando Christopher David. Effect of herbal medicine and its biochemical implication. Int. J Adv. Biochem. Res. 2020;4(2):46-57. DOI: 10.33545/26174693.2020.v4.i2a.130

10. Leung AY. Chinese Herbal Remedies, Universe Books, New York 124.

11. Londhe VY, Khogta SM, Barve KH. Improved antiarthritic activity of ginger extract, a traditional medicine, using novel drug delivery approach Journal of Complementary and Integrative Medicine 2020.

12. Osawa T. Japan: Japan Scientific Societies Press; 1994.Novel natural antioxidants for utilization in food and biological system 241-51, 48.

13. Okoli CO, Akah PA, Onuoha NJ, Okoye TC, Nwoye AC, Nworu CS. Acanthus montanus: An experimental evaluation of the antimicrobial, anti-inflammatory and immunological properties of a traditional remedy for furuncles. BMC Complement Altern Med 2008;8:27.

14. Packer L, Rimbach G, Virgili F. Antioxidant activity and biological properties of a procyanidin-rich extract from pine (Pinus maritima) bark, pycnogel. Free RadicBiol Med 1999;27:704-24.

15. Plummer DT. An Introduction to Practical Biochemistry. Mc Graw Hill Education (India) Private Limited. Third Edition 1987, 157-181.

16. Rahman K. Historical perspective on garlic and cardiovascular disease. J Nutr 2001;131:977S-979S.

17. Rahman K. Garlic and aging: new insights into an old remedy. Ageing Res Rev 2003;2:39-56.

18. Shahidi F, Wanasundara PKJPD. Phenolic antioxidants. Food Sci. Nutr. 1992;32:67-103.

19. Venkataraman ND, Clement Atlee W, Purushoth Prabhu T, Surya G, Kannan R, Sheik Nasar I. Evaluation of Invitro Anti-Arthritic Potential of Aerial Parts of Ipomoeapes- caprae (L.) R. Brand Estabilishment of Its Mechanism of Action. Research Journal of Pharmaceutical, Biological and Chemical Sciences 2013;4(2):1561-65.

20. Langner E, Greifenberg S, Gruenwald J. Ginger: history and use. Advance Thera 1998;15:25-44. 